\title{
Percutaneous Mechanical Thrombectomy of Submassive Pulmonary Embolism and Extensive Deep Venous Thrombosis for Early Thrombus Removal
}

\author{
Eun-Ah Jo', Kwang Woo Choi ${ }^{1}$, Ahram Han ${ }^{1}$, Sanghyun Ahn ${ }^{1}$, Sangil Min ${ }^{1}$, Hwanjun Jae ${ }^{2}$, \\ Myungsu Lee ${ }^{2}$, and Seung-Kee Min' \\ 'Division of Vascular Surgery, Department of Surgery, ${ }^{2}$ Department of Radiology, Seoul National University College of Medicine, Seoul, \\ Korea
}

\begin{abstract}
Traditional treatment with anticoagulation in nonfatal submassive pulmonary embolism can result in serious sequelae of chronic thromboembolic pulmonary hypertension or poor exercise tolerance, and functional impairment. To prevent long-term complications in previously healthy young patients, other treatment options to actively resolve existing thrombi should be considered. Despite recommendations for use in only severe clinical presentations, endovascular interventional techniques could serve as suitable treatment options for such patients. Here we report the case of a previously healthy 23-year-old female with submassive pulmonary embolism and extensive deep vein thrombosis in the inferior vena cava down to the right popliteal vein. The patient was initially treated with catheterdirected thrombolysis. However, she continued to show extensive venous thrombosis and pulmonary embolism. Percutaneous thrombectomy and aspiration using an AngioJet successfully removed the main pulmonary artery embolism and venous thrombus. The patient's recovery was uneventful, and 3-month follow-up showed no signs of recurrence or discomfort.
\end{abstract}

Key Words: Pulmonary embolism, Deep vein thrombosis, Mechanical thrombolysis, Thrombolytic therapy
Received August 10, 2021

Revised December 9, 2021

Accepted December 20, 2021

Published on December 31, 2021

\section{Corresponding author: Seung-Kee Min}

Division of Vascular Surgery, Rm 5313, Biomedical Research Institute, Seoul

National University Hospital, 101 Daehakro, Jongno-gu, Seoul 03080, Korea

Tel: 82-2-2072-0297

Fax: 82-2-766-3975

E-mail: skminmd@snuh.org

https://orcid.org/0000-0002-1433-2562

Copyright (c) 2021 The Korean Society for Vascular Surgery

This is an Open Access article distributed under the terms of the Creative Commons Attribution Non-Commercial License (http://creativecommons.org/licenses/by-nc/4.0) which permits unrestricted non-commercial use, distribution, and reproduction in any medium, provided the original work is properly cited.

Cite this article; Vasc Specialist Int 2021. https://doi.org/10.5758/vsi.210061

\section{INTRODUCTION}

Recent studies have shown that up to $41 \%$ of previously healthy patients who developed acute submassive pulmonary embolism (PE) displayed poor exercise tolerance and self-reported functional impairment [1-7]. Furthermore, unresolved PE leads to chronic thromboembolic pulmonary hypertension (CTEPH) in approximately 3\% of patients, who are at higher risk of recurrent venous thromboembolism (VTE), which is often fatal with severe cardiopulmonary impairment [3-8]. These long-term complications of acute PE, also called "post-PE syndrome," are becoming increas- ingly recognized. Persistent perfusion defects due to unresolved thrombi are among its main determinants. Despite anticoagulant therapy, long-term resolution is achieved in an estimated $70 \%$ to $85 \%$ of all patients [6]. The availability of various new catheter-based approaches for the treatment of acute PE has opened a vast field of research to improve both short- and long-term outcomes in such patients [9]. The percutaneous rheolytic thrombectomy device (AngioJet system; Boston Scientific, Marlborough, MA, USA) combines the advantages and benefits of the clot fragmentation technique and catheter-directed thrombolysis (CDT), allowing for the rapid dissolution and removal of 
large emboli $[10,11]$. The case report was approved by the Institutional Review Board of the Seoul National University Hospital (IRB no. 2102-107-1197).

\section{CASE}

A previously healthy 23-year-old female presented with right lower limb swelling for one day. One month prior, she was mildly injured with contusions to the face and both lower limbs as a passenger in a traffic accident. Physical examination showed a markedly increased diameter of the right versus left lower limb. Initial vital signs revealed an increased heart rate of 113 beats/min and fever up to $38.6^{\circ} \mathrm{C}$ but normotension. Laboratory tests showed elevated D-dimer level and slightly increased levels of cardiac biomarkers. Bedside echocardiography revealed no cardiac abnormalities. Details of the patient's initial clinical characteristics are summarized in Table 1.

Computed tomography angiography (CTA) of the lower limb and chest showed extensive DVT in the inferior vena cava (IVC) and right iliofemoral to popliteal veins as well as a submassive PE involving the right main and left lower segmental pulmonary arteries (Fig. 1)

Anticoagulation treatment was initiated consisting of subcutaneous enoxaparin $1 \mathrm{mg} / \mathrm{kg}$ twice daily. Considering the patient's young age and acute presentation, a strategy of early thrombus removal was preferred. After the insertion of an infrarenal IVC filter (Celect; Cook Medical, Bloomington, IA, USA), CDT with recombinant tissue plasminogen activator (Actilyse; Boehringer Ingelheim, lngelheim, Germany) was performed via the right popliteal vein at an infusion dose of $0.8 \mathrm{mg} / \mathrm{h}$ for 21 hours. Follow-up 24-hour venography showed a remnant thrombus, and pharmacomechanical thrombectomy (PMT) using an AngioJet was performed from the IVC down to the femoral vein. Balloon angioplasty was performed with a Mustang (Boston Scientific) $10 \mathrm{~mm} \times 60 \mathrm{~mm}$ to the right common iliac vein (Fig. 2). Anticoagulation was changed to rivaroxaban $15 \mathrm{mg}$ twice daily for 3 weeks.

Follow-up CTA performed 5 days after PMT showed a reduced burden of DVT but no change in PE extent. After discussion with experienced radiologists and sufficient informed consent was provided by the patient, aspiration and PMT of the PE using an AngioJet was performed and

Table 1. Initial clinical characteristics and test results

\begin{tabular}{|c|c|c|}
\hline Characteristic & Patient & Reference value \\
\hline \multicolumn{3}{|l|}{ Patient characteristic } \\
\hline Weight (kg) & 55.2 & \\
\hline Height $(\mathrm{cm})$ & 158 & \\
\hline Body mass index $\left(\mathrm{kg} / \mathrm{m}^{2}\right)$ & 22.1 & \\
\hline \multicolumn{3}{|l|}{ Vital sign } \\
\hline Blood pressure systolic/diastolic $(\mathrm{mmHg})$ & $140 / 88$ & \\
\hline Pulse rate (beat/min) & 113 & \\
\hline Respiratory rate (breath/min) & 16 & \\
\hline Body temperature $\left({ }^{\circ} \mathrm{C}\right)$ & 38.6 & \\
\hline Oxygen saturation SpO2 (\%) & 99 & \\
\hline \multicolumn{3}{|l|}{ Bedside echocardiography } \\
\hline Left ventricular ejection fraction (\%) & $65-70$ & \\
\hline Right ventricle dilatation & None & \\
\hline \multicolumn{3}{|l|}{ Blood test } \\
\hline White blood cell $(\mu \mathrm{L})$ & 15,630 & $4,000-10,000$ \\
\hline Hemoglobin (g/dL) & 12.8 & $12-16$ \\
\hline Platelet count $(\mu \mathrm{L})$ & 197,000 & $130,000-400,000$ \\
\hline C-reactive protein $(\mathrm{mg} / \mathrm{dL})$ & 14.73 & $0-0.5$ \\
\hline D-dimer $(\mu \mathrm{g} / \mathrm{mL})$ & 35.47 & $0.04-0.49$ \\
\hline \multicolumn{3}{|l|}{ Cardiac biomarker } \\
\hline Creatinine kinase (IU/L) & 31 & $20-270$ \\
\hline Creatinine kinase-MB (ng/mL) & 1.1 & $0-6.6$ \\
\hline Troponin-I (ng/mL) & 0.03 & $0-0.028$ \\
\hline Brain natriuretic peptide $(\mathrm{pg} / \mathrm{mL})$ & 123 & $0-100$ \\
\hline
\end{tabular}


resulted in successful recanalization of the main pulmonary arteries (Fig. 3). The patient's vital signs were continuously monitored during the procedure and in the intensive care unit for 24 hours. No adverse events such as bradycardia, arrhythmia, hypotension, renal impairment, hemoptysis, or signs of hemorrhage occurred. The swelling improved dramatically, and the patient was discharged on hospitalization day 7 on rivaroxaban with class 11 compression stockings. Follow-up after 3 months on rivaroxaban showed no signs of recurrence or discomfort.
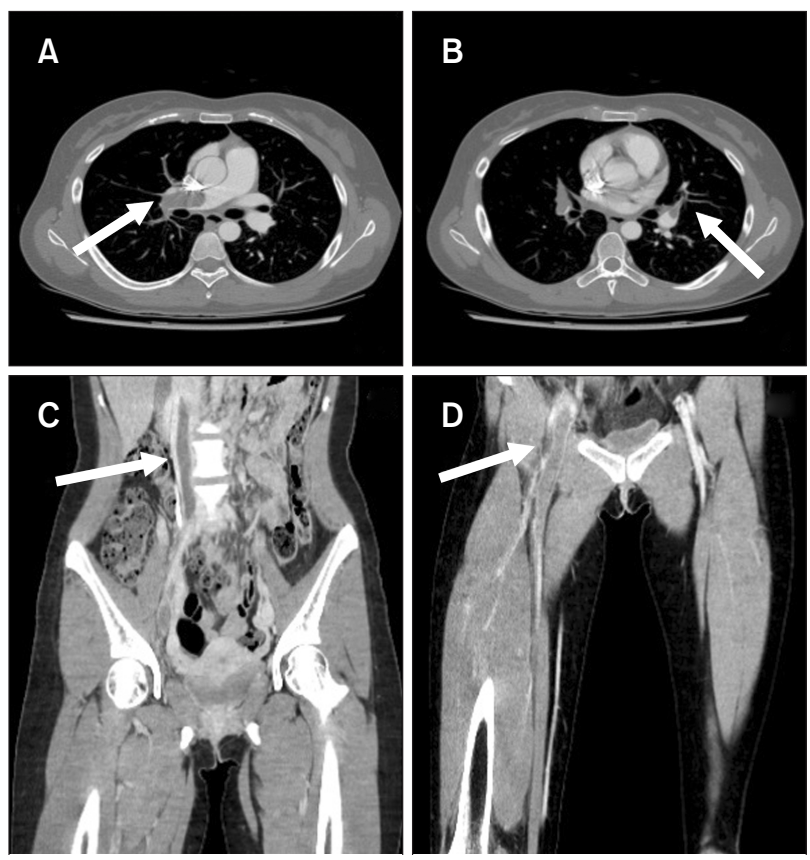

Fig. 1. Initial computed tomography angiography showed right main pulmonary artery thromboembolism (A), left lower lobe segmental artery pulmonary thromboembolism (B), inferior vena cava thrombus (C), and extensive deep vein thrombosis in right common iliac to popliteal vein (D).

\section{DISCUSSION}

Thrombus resolution in cases of PE with traditional treatment consisting of systemic heparinization followed by oral anticoagulation is initially trifling, and long-term resolution remains under debate $[5,6]$. Resolution was as low as $10 \%$ after 24 hours of treatment versus $50 \%$ at 2 to 4 weeks post-treatment. At 6 to 12 months after the initial diagnosis, $25 \%$ to $30 \%$ of patients showed only partial resolution $[3,5,6,8]$. After 3 months of treatment, the thrombus resolution reached a plateau phase and only very small improvements were seen thereafter, suggesting the occurrence of remodeling in the remaining clots to form permanent fibrous scars [3,5]. The resulting long-term complications consist of chronic functional limitations and a decreased quality of life [6].

CTEPH is the most severe form of post-PE syndrome, and its prognosis is poor in untreated patients $[1,6]$. Due to its nonspecific initial symptoms of dyspnea on exertion and fatigue, its diagnosis is often delayed. On delayed final diagnosis, most patients show severe functional impairment matching a New York Heart Association (NYHA) heart failure classification of 111 or IV [1,6-8]. The incidence of CTEPH after acute PE in patients without other major comorbidities is approximately 3\% [8]. However, the rate of less severe manifestations of post-PE syndrome is much higher. The results of the prospective Evaluation of Longterm Outcomes after Pulmonary Embolism (ELOPE) study demonstrated that almost half of acute PE patients have exercise limitations, a limited walking distance, and dyspnea at 1 year that adversely influence their quality of life [2]. In one prospective study of previously healthy patients with acute PE, $48 \%$ had a NYHA classification of 11 or higher that lasted over a 3-year follow-up period [6,7]. Therefore, the goal of treatment in acute PE should also include reducing and preventing long-term sequelae.

Therefore, PMT is an attractive treatment option since

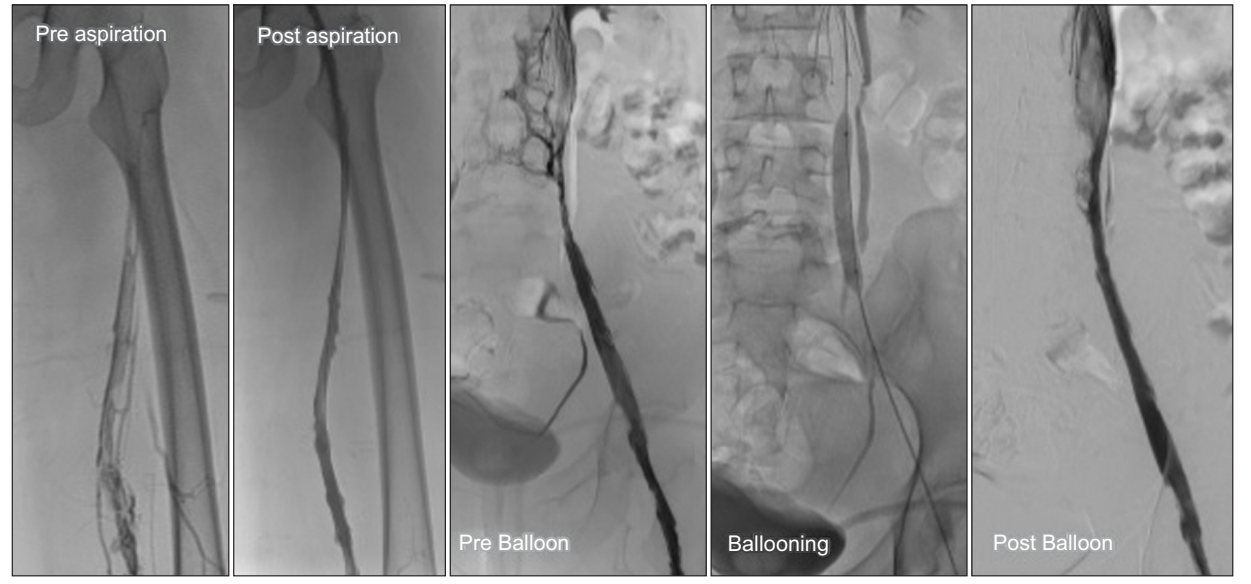

Fig. 2. In prone position, pharmacomechanical thrombectomy with AngioJet was performed via popliteal vein puncture, followed by balloon angioplasty with Mustang $10 \mathrm{~mm} \times 60 \mathrm{~mm}$ to right common iliac vein stenosis. 


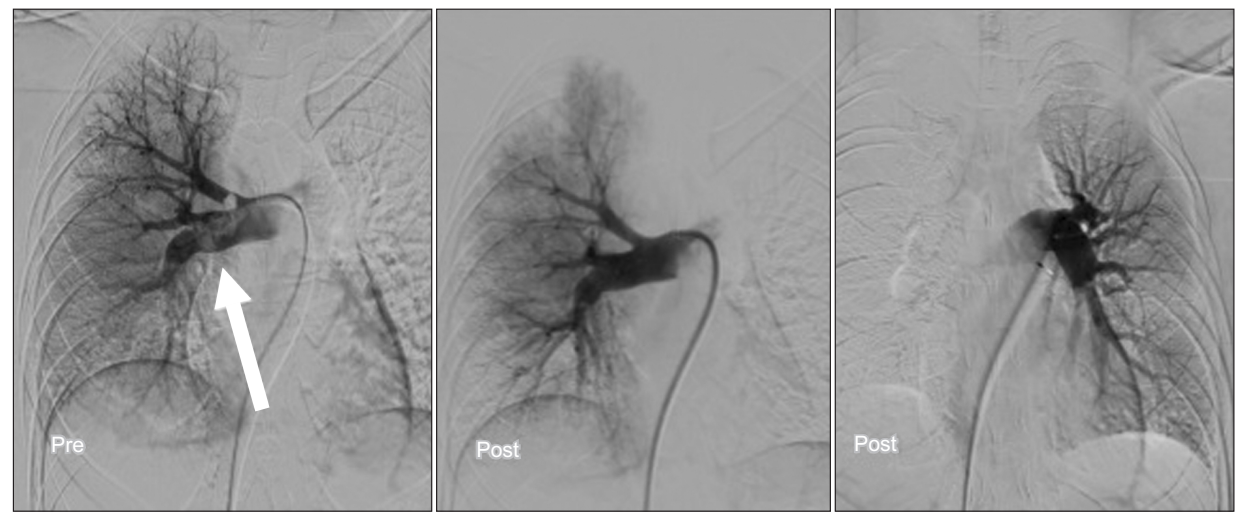

Fig. 3. Arteriography was initially undertaken through a 7-Fr sheath and a pigtail catheter was placed up to the main pulmonary vein. A large thrombus at the right main pulmonary artery (RPA) was checked and an 8Fr shuttle for aspiration thrombectomy was attempted followed by AngioJet Zealante for mechanical thrombectomy. Repeated aspiration and mechanical thrombectomy were undertaken and completion pulmonary arteriography showed that the RPA thrombus disappeared without distal embolism.

it limits the impact of thrombolytics and can extract central and peripheral emboli quickly and easily [10,12-14]. Although thrombus removal as a primary treatment for DVT was dropped from the American College of Chest Physicians guideline due to a lack of evidence of reducing post-thrombotic syndrome, the long-term results of PMT including those of the Catheter-directed Venous Thrombolysis (CaVenT) study now support PMT for patients with a high proximal DVT and low risk of bleeding, such as in this case [15]. In particular, in healthy young patients, rapid recovery and a return to daily activities is critical in improving the quality of life. In addition to prompt symptom relief, further aesthetic satisfaction may result in swelling improvements. However, caution should be exercised when preventing distal embolization in PMT, as PMT fragmentation can result in detrimental large emboli, particularly in cases of an extensive thrombus burden. In such cases, preventive IVC filter placement and CDT followed by adjunctive PMT can minimize complications and maximize treatment efficiency [14].

The AngioJet is a PMT system that removes large emboli by dissolution and fragmentation. In the management of PE, the reported AngioJet clinical success rate was 86.5\% with a major complication rate of $2.4 \%$ and minor complication rate of 7.9\% [12]. Conversely, a review by Kuo et al. [16] reported that specific catheter-related complications such as hemoptysis, pulmonary artery perforation, bradycardia, and hemoglobinuria were especially high with the AngioJet system [17]. Special care and technical considerations should be taken to prevent complications due to distal embolization. First, the "freshness" or duration of the thrombus occurrence is important. Thrombus organization and vessel wall remodeling occur as soon as 7 days and with time the thrombus becomes increasingly adherent to the vessel wall. Such a chronic thrombus requires a longer duration of treatment in the power pulse mode using larger amounts of thrombolytic agents. This is a known cause of bradycardia, hemoglobinuria, and hemoptysis with the AngioJet system [18]. Prior thrombolytic treatment, whether systemic or catheter-directed, can help alleviate the thrombus burden and enable easier dissolution. Second, as previously mentioned, filters or distal balloon placements can be used before the maceration process to mitigate the embolization. Compared to other PMT products, the AngioJet rheolytic system creates a Bernoulli effect that results in less distal embolization [19].

Furthermore, there is not yet sufficient data to prove the benefits of catheter-based approaches for the treatment of acute PE; thus, they are recommended for use in only highrisk or "massive" PE cases $[10,20]$. The present case, based on the American Heart Association classification, was a "submassive" PE due to the mildly elevated brain natriuretic peptide and troponin 1 levels and would not normally be recommended for such treatment. However, we decided to perform PMT because the patient was previously healthy, the right main pulmonary artery was occluded with a high risk of chronic functional impairment, and the risk of periprocedural complications was relatively low according to experienced interventionalists.

However, it must be noted that the prognostic stratification of PE in all major guideline committees is based on short-term mortality of patients with hypotension and right ventricular disease $[9,20]$. Chronic functional limitations and quality of life impairments were not considered. The lack of randomized trials, differences in clinical endpoints, and long-term follow-up data on the safety and efficacy of the routine use of PMT should not preclude its identification as an unsuitable treatment option. Clinical, radiological, and laboratory risks should also be used to drive the therapeutic 
decision-making process [9]. With careful patient selection and technical attention to preventing distal embolization and iatrogenic injury, PMT with an AngioJet could result in better and early recovery of symptoms, especially in healthy young patients with extensive VTE. Therefore, we recommend that this procedure be performed in high-volume centers by experienced interventionalists and multidisciplinary teams to manage possible complications.

\section{FUNDING}

None.

\section{CONFLICTS OF INTEREST}

The authors have nothing to disclose.

\section{ORCID}

Eun-Ah Jo

https://orcid.org/0000-0002-9324-4877

Kwang Woo Choi https://orcid.org/0000-0002-5476-1118

Ahram Han

https://orcid.org/0000-0002-3866-5214

Sanghyun Ahn

https://orcid.org/0000-0003-4308-4788

Sangil Min

https://orcid.org/0000-0002-0688-0278

Hwanjun Jae

https://orcid.org/0000-0002-0328-3400

Myungsu Lee

https://orcid.org/0000-0002-8320-5479

Seung-Kee Min

https://orcid.org/0000-0002-1433-2562

\section{AUTHOR CONTRIBUTIONS}

Concept and design: SKM. Analysis and interpretation: EAJ, KWC. Data collection: EAJ. Writing the article: EAJ, SKM. Critical revision of the article: AH, SA, SM. Final approval of the article: all authors. Statistical analysis: none. Obtained funding: none. Overall responsibility: SKM.
1) Held M, Kolb P, Grün M, Jany B, Hübner G, Grgic A, et al. Functional characterization of patients with chronic thromboembolic disease. Respiration 2016;91:503-509.

2) Kahn SR, Hirsch AM, Akaberi A, Hernandez P, Anderson DR, Wells PS, et al. Functional and exercise limitations after a first episode of pulmonary embolism: results of the ELOPE prospective cohort study. Chest 2017;151:1058-1068.

3) Kahn SR, Houweling AH, Granton J, Rudski L, Dennie C, Hirsch A. Longterm outcomes after pulmonary embolism: current knowledge and future research. Blood Coagul Fibrinolysis 2014;25:407-415.

4) Kline JA, Steuerwald MT, Marchick MR, Hernandez-Nino J, Rose GA. Prospective evaluation of right ventricular function and functional status 6 months after acute submassive pulmonary embolism: frequency of persistent or subsequent elevation in estimated pulmonary artery pressure. Chest 2009;136:1202-1210.

5) Klok FA, van der Hulle T, den Exter PL, Lankeit M, Huisman MV, Konstantinides S. The post-PE syndrome: a new concept for chronic complications of pulmonary embolism. Blood Rev 2014;28:221-226.

6) Sista AK, Klok FA. Late outcomes of pulmonary embolism: the post-PE syndrome. Thromb Res 2018;164:157162.

7) Stevinson BG, Hernandez-Nino J, Rose G, Kline JA. Echocardiographic and functional cardiopulmonary problems 6 months after first-time pulmonary embolism in previously healthy patients. Eur Heart J 2007;28:25172524.

8) Ende-Verhaar YM, Cannegieter SC, Vonk Noordegraaf A, Delcroix M, Pruszczyk P, Mairuhu AT, et al. Incidence of chronic thromboembolic pulmonary hypertension after acute pulmonary embolism: a contemporary view of the published literature. Eur Respir J 2017;49:1601792.

9) Rali PM, Criner GJ. Submassive pulmonary embolism. Am J Respir Crit Care Med 2018;198:588-598.

10) Tapson VF, Jimenez D. Catheter-based approaches for the treatment of acute pulmonary embolism. Semin Respir Crit Care Med 2017;38:73-83.

11) Villalba L, Nguyen T, Feitosa RL Jr, Gunanayagam P, Anning N, Dwight K. Single-session catheter-directed lysis using adjunctive power-pulse spray with AngioJet for the treatment of acute massive and submassive pulmonary embolism. J Vasc Surg 2019;70:1920-1926.

12) Ferrigno L, Bloch R, Threlkeld J, Demlow T, Kansal R, Karmy-Jones R. Management of pulmonary embolism with rheolytic thrombectomy. Can Respir J 2011;18:e52-e58. 
13) Song XJ, Liu ZL, Zeng R, Liu CW, Ye $W$. The efficacy and safety of angiojet rheolytic thrombectomy in the treatment of subacute deep venous thrombosis in lower extremity. Ann Vasc Surg 2019;58:295-301.

14) Lee JK, Kim KY, Byun SJ. Safety and efficacy of aspiration thrombectomy or pharmacomechanical thrombectomy after catheter-directed thrombolysis for the treatment of acute iliofemoral deep vein thrombosis. Vasc Specialist Int 2020;36:144-150.

15) Enden T, Haig Y, Kløw NE, Slagsvold CE, Sandvik L, Ghanima W, et al. Long-term outcome after additional catheter-directed thrombolysis versus standard treatment for acute iliofemoral deep vein thrombosis (the CaVenT study): a randomised controlled trial. Lancet 2012;379:31-38.

16) Kuo WT, Gould MK, Louie JD, Rosenberg JK, Sze DY, Hofmann LV. Catheter-directed therapy for the treatment of massive pulmonary embolism: systematic review and meta-analysis of modern techniques. J Vasc Interv Radiol 2009;20:1431-1440.

17) Margheri M, Vittori G, Vecchio S, Chechi T, Falchetti E, Spaziani G, et al. Early and long-term clinical results of AngioJet rheolytic thrombectomy in patients with acute pulmonary embolism. Am J Cardiol 2008;101:252-258.
18) Hogg K, Kimpton M, Carrier M, Coyle D, Forgie M, Wells P. Estimating quality of life in acute venous thrombosis. JAMA Intern Med 2013;173:10671072.

19) Li K, Cui M, Zhang K, Liang K, Liu H, Zhai S. Treatment of acute pulmonary embolism using rheolytic thrombectomy. Eurolntervention 2021;17:e158e166.

20) Sista AK, Kuo WT, Schiebler M, Madoff DC. Stratification, imaging, and management of acute massive and submassive pulmonary embolism. Radiology 2017;284:5-24. 